\title{
Geophysical Imaging of Subsurface Earthquake-induced Liquefaction Features at Christchurch Boys High School, Christchurch, New Zealand
}

\author{
David C. Nobes ${ }^{1}$, Sarah Bastin ${ }^{1}$, Gemma Charlton ${ }^{1}$, Rowan Cook ${ }^{1}$, Max Gallagher ${ }^{1}$, Hamish Graham ${ }^{1, *}$ \\ Daniel Grose ${ }^{1, \uparrow}$, Joanne Hedley ${ }^{1}$, Scott Sharp-Heward ${ }^{2}$ and Sean Templeton ${ }^{1}$ \\ ${ }^{1}$ Department of Geological Sciences, University of Canterbury, Private Bag 4800, Christchurch 8140, New Zealand \\ Email: david.nobes@canterbury.ac.nz \\ ${ }^{2}$ Department of Soil and Physical Sciences, Lincoln University, PO Box 84, Lincoln 7647, New Zealand \\ *Now at Environment Canterbury, Christchurch, New Zealand \\ ${ }^{\dagger}$ Now at Tonkin \& Taylor, Christchurch, New Zealand
}

\begin{abstract}
On February 22, 2011, a magnitude $\mathrm{M}_{\mathrm{w}} 6.2$ earthquake affected the Canterbury region, New Zealand, resulting in many fatalities. Liquefaction occurred across many areas, visible on the surface as "sand volcanoes", blisters and subsidence, causing significant damage to buildings, land and infrastructure.

Liquefaction occurred at a number of sites across the Christchurch Boys High School sports grounds; one area in particular contained a piston ground failure and an adjacent silt volcano. Here, as part of a class project, we apply near-surface geophysics to image these two liquefaction features and determine whether they share a subsurface connection. Hand auger results enable correlation of the geophysical responses with the subsurface stratigraphy.

The survey results suggest that there is a subsurface link, likely via a paleo-stream channel. The anomalous responses of the horizontal loop electromagnetic survey and electrical resistivity imaging highlight the disruption of the subsurface electrical properties beneath and between the two liquefaction features. The vertical magnetic gradient may also show a subtle anomalous response in this area, however the results are inconclusive. The ground penetrating radar survey shows disruption of the subsurface stratigraphy beneath the liquefaction features, in particular sediment mounding beneath the silt ejection ("silt volcano") and stratigraphic disruption beneath the piston failure.

The results indicate how near-surface geophysics allow the characteristics of liquefaction in the subsurface to be better understood, which could aid remediation work following liquefaction-induced land damage and guide interpretation of geophysical surveys of paleoliquefaction features.
\end{abstract}

\section{Introduction}

On February 22, 2011, a Mw 6.2 earthquake occurred beneath the city of Christchurch, New Zealand (Davey, 2011; Kaiser et al., 2012). Widespread damage, destruction and fatalities occurred, not the least of which was the widespread liquefaction that was experienced throughout the Christchurch area. The main cause of damage to infrastructure and land was the liquefaction of recent fluvial deposits, which caused subsidence, lateral spreading and sediment ejection (Cubrinovski et al., 2010).

Liquefaction occurs when a mass of soil loses a large percentage of its shear resistance, when subjected to monotonic, cyclic or shock loading, and flows in a manner resembling a liquid until the shear stresses acting on the mass are as low as the reduced shear resistance (Sladen et al., 1985). Earthquake liquefaction increases the pore pressure in sandy layers because of the collapse of their granular structure. This in turn causes the soil to lose its shear strength which results in liquefaction. Liquefaction creates structures known as "sand volcanoes" or "sand blows" which erupt to the surface through thin feeder tubes and form volcano-like surface expressions that can "erupt" through soil and even through hardened surfaces of concrete or tarseal (Reid et al., 2010).

A number of studies have demonstrated the efficacy of geophysical imaging to locate paleoliquefaction features, particularly sand blows, including electrical and electromagnetic mapping (Wolf et al., 1998, 2006; Tuttle et al., 1999), ground penetrating radar (Liu and Zhou, 2000; Liu and Li, 2001; Tatsuya et al., 2002; Hsu et al., 2005; Maruya et al., 2006; Al-Shukri et al., 
Journal of Environmental and Engineering Geophysics

2006), and borehole and cross-hole radar (Kayen et al., 2000, 2005). However, those studies were primarily directed towards locating such features as sand blows in the subsurface or changes in the physical properties associated with liquefaction, whereas such liquefaction artefacts were present on the surface as sand volcanoes after the Christchurch earthquakes. What we were looking for was the subsurface link between adjacent surface features, and from those features to a possible path for liquefied sediment at depth, rather than mapping such features in the subsurface. Thus the target was slightly different, albeit related.

Here we present the results of a class project study that examined the subsurface links between a "silt volcano" and a piston failure, and their possible relation to a buried paleochannel. A range of methods were used, including electromagnetic (EM) mapping, electrical imaging (EI), total magnetic field and magnetic gradient measurements, and ground penetrating radar (GPR). The magnetic field measurements contributed little or no information because the underlying materials were predominantly non-magnetic and the results were strongly influenced by cultural features such as the cricket practice nets. Thus we focus here on the EM, EI and GPR results. In addition, a number of cores were obtained, which provided some correlation for the geophysical results and calibration of the water table.

\section{Site Description, Survey Design and Data Processing}

\section{Site Description}

During the Mw 6.2 earthquake of February 22, 2011, liquefaction occurred at many spots on the sports grounds at Christchurch Boys High School (CBHS, Fig. 1). CBHS is sited northwest of the Christchurch central city, and is underlain by interbedded sands, silts and gravels of the Christchurch and Springston formations (Brown et al., 1988; Brown and Weeber, 1992). These formations were deposited by the Waimakariri River (Shulmeister et al., 1999) as it avulsed across the Canterbury Plains and into paleo-flood channels. The most recent avulsion is represented by the Selwyn soils (Shulmeister et al., 1999), which have high liquefaction potential because of their average grain size, lack of compaction and high pore space (Cubrinovski et al., 2010). The surrounding Canterbury Plains are underlain by a series of normal faults that are mostly non-active, but some faults have been re-activated as strike-slip faults to accommodate excess strain (Dorn et al., 2010; Davey, 2011; Kaiser et al., 2012).

Many of the CBHS liquefaction features appeared to be approximately aligned, suggesting a possible subsurface connection. Most of the liquefaction features were quickly remediated, and sporting activities resumed within a short period of time (Dods, pers. comm., 2011). Two features (Fig. 1) were situated just outside the main sporting grounds areas, and thus were accessible for further investigation. The two features on first inspection appeared to be possibly linked: one was a "piston" failure that was subsequently remediated by infilling with soil and fine sand; the adjacent feature was a "silt volcano" that was elongate in the direction of what appeared to be a narrow (a few centimeters width at most), relatively linear rupture in the ground surface. A similar feature was photographed shortly after the earthquake and before remediation (Fig. 2). Thus, we focussed on investigating the possible links between the two features.

The site survey was set out to ensure that both features were covered by any investigation; thus the coverage of the geophysical surveys was extended beyond the surface expressions of the liquefaction. The site was $28-\mathrm{m}$ long in a west-northwest to east-southeast direction, and $10 \mathrm{~m}$ in a transverse north-northeast to south-southwest direction (Figs. 1 and 3). The central WNW-ESE longitudinal line was parallel to the axis of the two liquefaction features, and was approximately centered on the two features. The perpendicular survey lines were oriented NNE-SSW. Four geophysical techniques were utilized: horizontal loop electromagnetic (HLEM) mapping using a Geonics EM31; electrical imaging (EI) using a Campus Tigre system with 32 electrodes; a Sensors \& Software pulsEKKO 100A GPR system using 100 and $200 \mathrm{MHz}$ antennas, initially; and a Geometrics G-856 magnetometer/gradiometer. The magnetic results yielded little or no information, as noted earlier, and so we focus on the EM31, EI and GPR results.

\section{EM31}

Our initial surveys used a Geonics EM31 HLEM ground conductivity meter. The principles of HLEM are well described in numerous textbooks (e.g., Milsom and Eriksen, 2011) and technical papers (e.g., McNeill, 1990). A small transmitting coil at one end of the instrument sends a $9.8-\mathrm{kHz}$ EM signal into the ground, where electric currents are induced to flow. These induced currents in turn generate secondary magnetic fields that are measured at a receiving coil at the other end of the instrument, $3.66 \mathrm{~m}$ from the transmitting coil. In the normal HLEM orientation of the EM31 and for low electrical conductivities, the depth of penetration is approximately 1.5 times the coil separation, or about $5.5 \mathrm{~m}$. The EM31 is sensitive to features about $2 \mathrm{~m}$ out to either side of the instrument, and about $1 \mathrm{~m}$ off the ends of the instrument booms that hold the transmitting and receiving coils.

The HLEM response consists of two modes or phases. The real part is aligned (in phase) with the 
Nobes et al.: Geophysical Imaging of Liquefaction Features

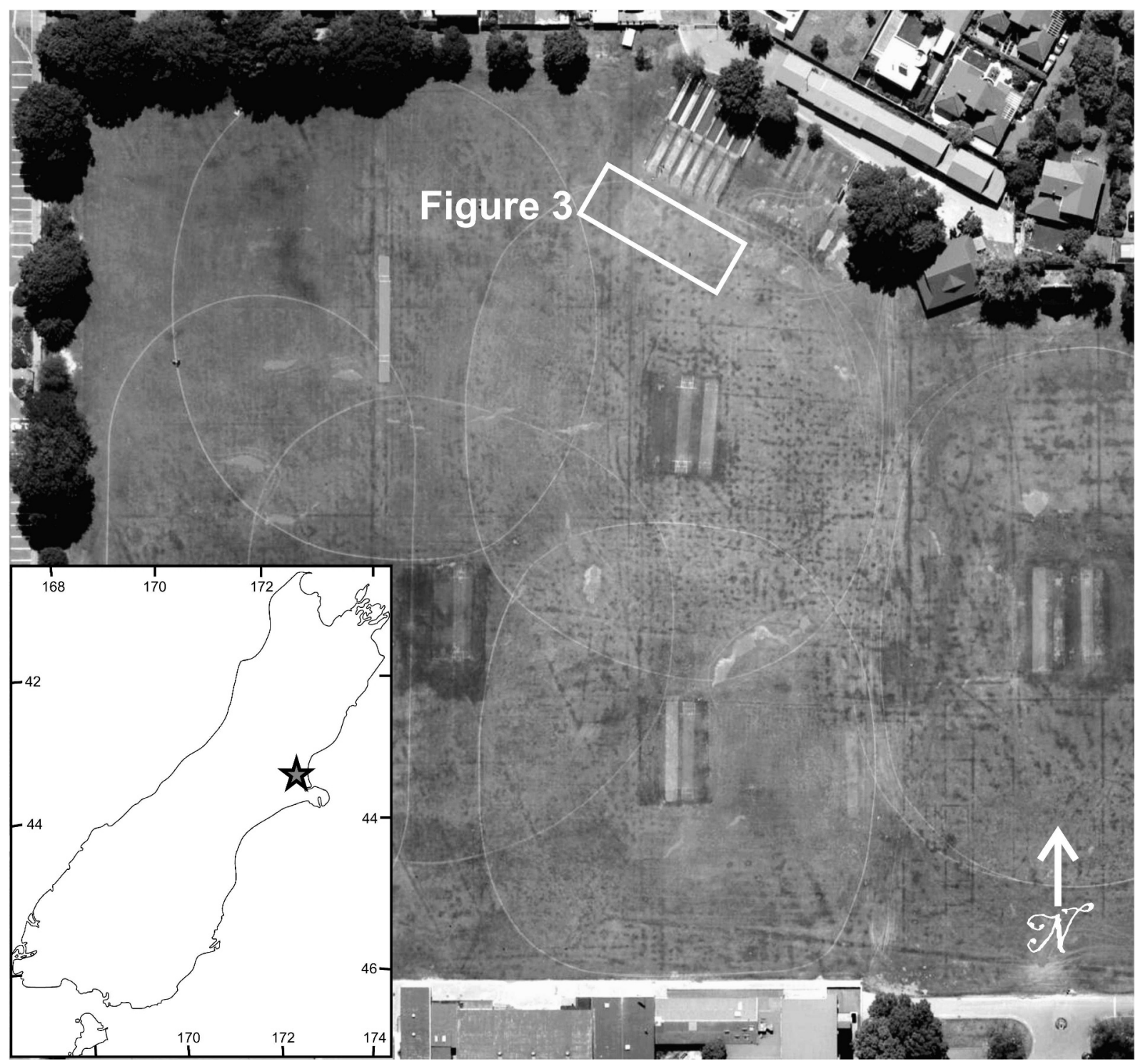

Figure 1. Air photo of the CBHS sports grounds soon after the February 22, 2011 earthquake. The areas of liquefaction are readily apparent as grey patches. The survey site (Fig. 3) is indicated (rectangle, center top). Inset: Location of Christchurch (star) relative to the South Island of New Zealand.

transmitted signal, and is akin to the signal that a metal detector uses; its response is expressed in parts per thousand (ppt) of the transmitted signal. The imaginary part or quadrature mode is out of phase with the transmitted signal, and is linearly related to the subsurface electrical conductivity at low conductivities, as was present in this situation; the quadrature response is given in millisiemens per meter $(\mathrm{mS} / \mathrm{m})$.

EM31 mapping was done on 29 NNE-SSW survey lines, each $1-\mathrm{m}$ apart, at 21 stations spaced $0.5 \mathrm{~m}$ along the 10-m long lines (Fig. 3). Two readings were taken at each station: one reading was with the EM31 boom parallel to the survey line and a second with the boom perpendicular. The two orientations allow for the directionality in the EM31 response (see, e.g., Nobes, 1999b, 2007), which can highlight or even detect linear features if the background conductivity is changing significantly (Nobes and Wallace, 2007).

Almost every survey participant used the EM31 for at least two lines. The consequent differences in instrument heights, in particular, caused changes in the EM31 response from one line to the next (Fig. 4). This effect can be corrected by using the approach as described by Field et al. (2001) and Nobes (1999a). The median response is removed for each line in turn, leaving a residual response. The median is used rather than the mean, because the median is a more robust estimator of a background EM31 response. The median 
Journal of Environmental and Engineering Geophysics

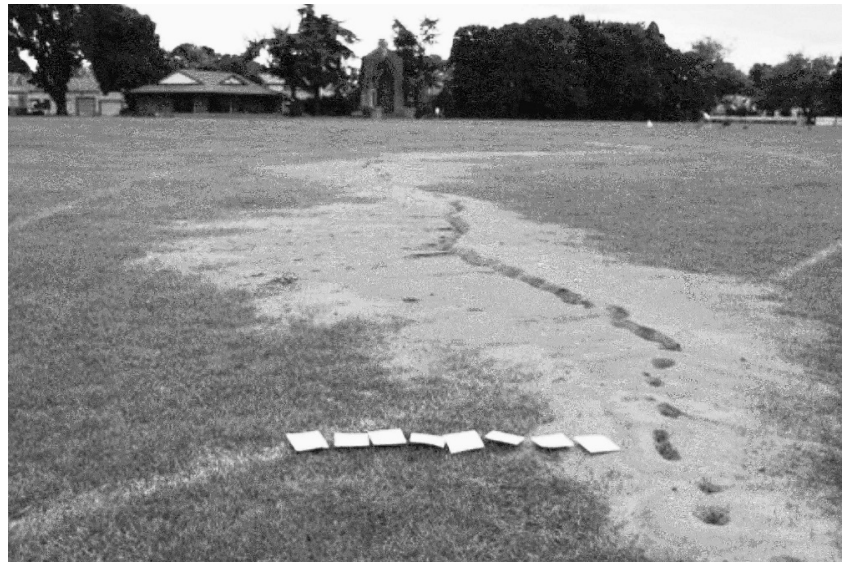

Figure 2. Photograph of one of the "silt volcanoes" caused by liquefaction at the CBHS site before removal of the ejected silt. Note that the mound is elongate in the WNW-ESE direction, in this case, and has a narrow vent. (Photograph courtesy of S. Dods of CBHS). No photo of the piston failure before remediation is available.

is less affected by anomalous values that may be indicative of a target or targets along a survey line. The reliability of the data acquisition and the effects of the different operators can be tested by repeating selected lines. The comparison of repeated readings (Fig. 4) shows good repeatability with a high degree of correlation $\left(\mathrm{R}^{2}=0.92\right)$. The raw repeated data (Fig. 4(A)) highlight the consistent differences (e.g., Line 8 data oriented parallel to the survey line, labelled

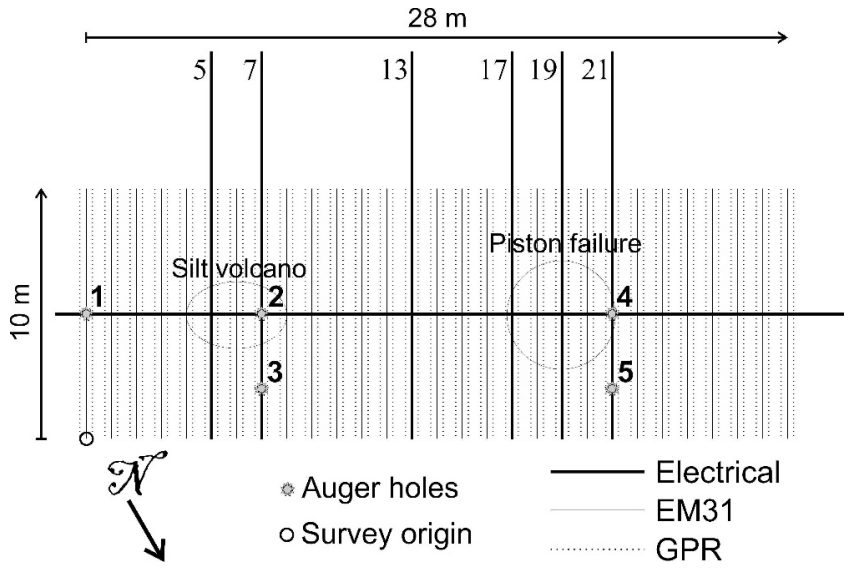

Figure 3. Layout of the CBHS liquefaction survey site relative to the approximate locations of the silt volcano (left) and piston failure (right), as marked. The EM31 lines are shown as light solid lines, and were spaced every meter. The electrical imaging lines are shown bold and labeled, and extend beyond the main survey area. The GPR lines are shown dotted and fall $0.25 \mathrm{~m}$ on either side of the EM31 lines, with a net $0.5-\mathrm{m}$ line spacing. The five auger hole locations are shown by stars.
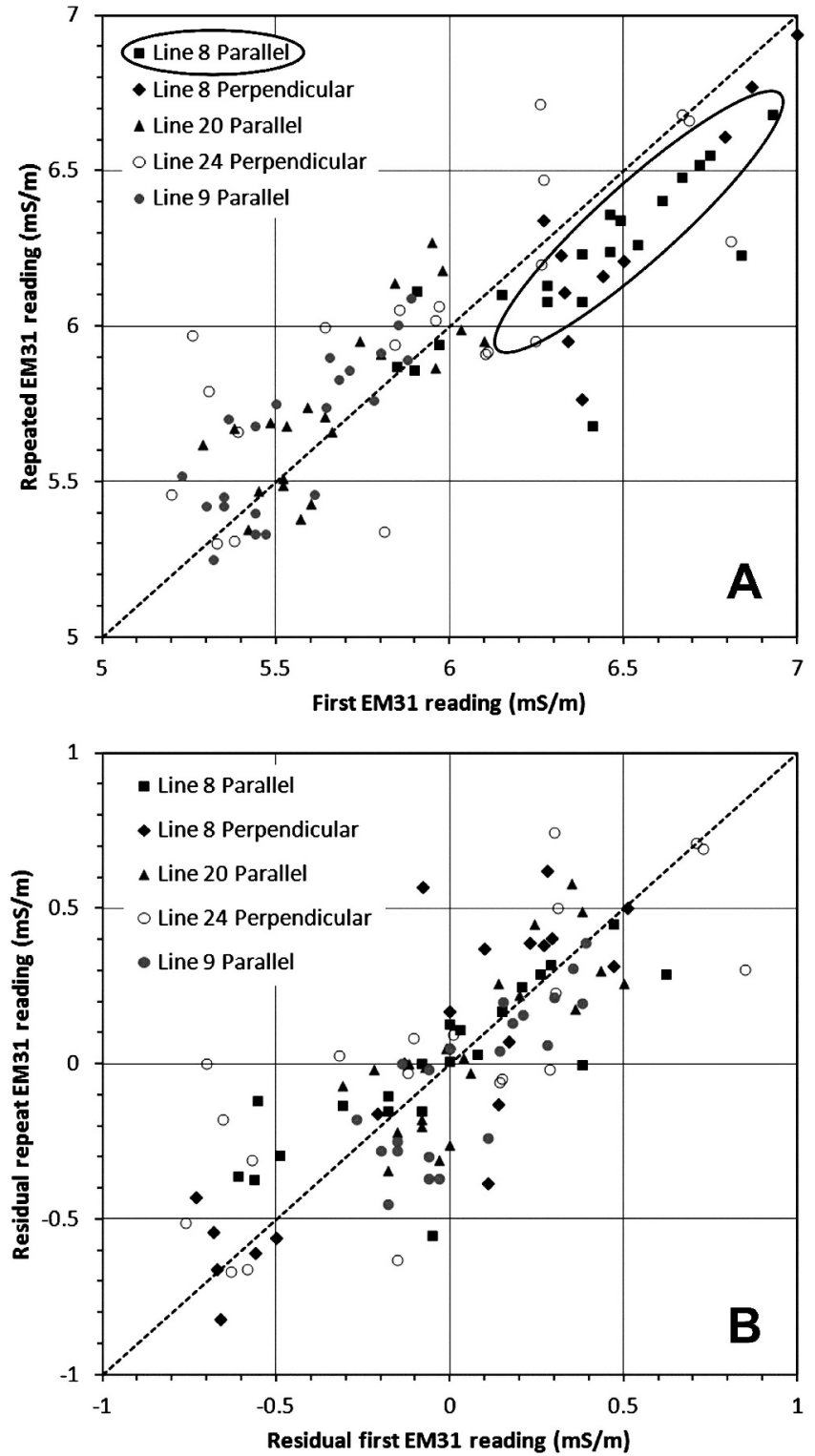

Figure 4. A) The raw repeated readings for the EM31 survey show the generally good correlation, but also the obvious offset from the 1:1 trend line (bold dashed). The linear, but offset trend of the Line 8 parallel data is highlighted as an example. B) The residual repeated readings after removal of the median. The data now cluster about the 1:1 trend line with no offset. The correlation coefficient is high for both raw and residual data, of the order of $R^{2}=0.9$.

"Line 8 parallel") so that when the median is removed the data cluster nicely and randomly about a 1:1 trend (Fig. 4(B)).

Both raw and residual EM31 data were gridded and contoured using Surfer. A number of gridding techniques were tested for consistency in the contoured data. The results presented here all used the krigging 


\section{Nobes et al.: Geophysical Imaging of Liquefaction Features}

gridding technique. The oriented EM31 data were examined separately and when combined both as the average of the oriented data and as the difference between the oriented data. The data all showed similar patterns, which will be discussed in the next section. For brevity and simplicity, only the residual of the mean oriented data will be shown.

\section{Electrical Imaging}

Electrical imaging (EI) is based on the well established technique of electrical resistivity sounding and resistivity profiling (e.g., Milsom and Eriksen, 2011). Multiple electrodes are set out across a site, and then a control box, usually connected to a laptop or other storage device, carries out an electrical resistivity survey by turning the electrodes on and off in sequence. Different geometries can be programmed to be completed as directed via the laptop and control box for the EI system. In this case, a Campus Tigre system was used, which was capable of carrying out a profile with up to 128 electrodes. In our case, we used only 32 electrodes at a time, given the small size of the site.

Because of time constraints, only a limited number of EI cross-sections, seven in total (Fig. 3), could be obtained for the Wenner electrode configurations and one (a longitudinal profile) was done using the Schlumberger array as well (e.g., Milsom and Eriksen, 2011). Two NNE-SSW lines (5 and 7) were placed to cross the silt volcano location, three NNE-SSW lines (17, 19 and 21) crossed the piston failure, one central longitudinal WNW-ESE profile crossed both features, and one central NNE-SSW profile (13) was acquired between the two features (Fig. 3). The NNE-SSW profiles used 32 electrodes with 0.5 -m electrode spacing, so each line was $15.5-\mathrm{m}$ long because the first electrode was at the start of the line. The profile centers were offset to the SSW to align the electrodes with the start of the grid, and so that the cross-section profiles might be centered more along what appeared to be a paleochannel. The longitudinal profile used 32 electrodes with $1 \mathrm{~m}$ spacing. Again, the profile center was offset to the ESE to align the electrodes with the survey grid. All electrodes were emplaced and watered to ensure good electrical contact. Even so, occasional poor contact occurred. These "bad" data points were removed from the resultant data sets before data inversion and modeling. In general, there were only six bad data points out of 155 points, always associated with one electrode with poor contact. The data quality was good; each data point consisted of two successive measurements, and the repeat values always agreed within a few percent. No lines were repeated.

Once the bad points were removed, each of the data sets was modeled using the RES2DINV inversion program, which is based on the process outlined by Loke and Barker (1996). The best-fit model was calculated for each data set using a robust inversion scheme. In addition to the best-fit model, the model cell uncertainties and sensitivities were calculated. Such information shows if the errors are randomly distributed or are systematic. Often, for example, errors will be greatest at the boundaries between highly resistive and more conductive bodies, and as a result of overlapping readings, the greatest sensitivities and least uncertainties are in the shallow cells (near the surface). In contrast, the greatest uncertainties occur in the deeper cells and along the edges where there is little or no overlap in measurements.

An example of the processing steps and results is shown for the longitudinal Wenner profile (Fig. 5). The longitudinal Schlumberger profile yields the same features and pattern of subsurface resistivities, so only the Wenner results are presented here. We note that the reference for the electrical imaging profiles is the first electrode, which is shifted $1 \mathrm{~m}$ ESE from the origin of the site. Because the line is $31-\mathrm{m}$ long across a site that is $28 \mathrm{~m}$ in extent, and the electrodes are 1-m apart, we placed the electrodes on the meter marks to align the electrical imaging with the other survey grids. The approximate extents of the surface liquefaction features are also shown in Fig. 5.

The measured profile (Fig. 5(A)) shows the apparent resistivity as a function of position across the horizontal axis and pseudo-depth down the vertical axis. The individual readings for each pair of voltage and current electrodes are contoured to yield the resistivity pseudo-section. The RES2DINV program then starts with a simple layered model, determines the error (misfit) between the model response and the measured response, and step by step alters the subsurface resistivity in each cell until the minimum misfit model is found (Fig. 5(B)). The normalized difference between the model and measured responses is determined, i.e., the root-mean-squared (RMS) error, in this case 3.4\%. The subsurface resistivity model is thus determined (Fig. 5(C)).

In addition, we can determine the relative sensitivity of each cell to changes in the data (Fig. 5(D)) and the relative uncertainty in each cell resistivity (Fig. 5(E)). The end cells are not truncated in this case, so the edges are distorted. Because of the lack of overlapping readings, the greatest sensitivities and uncertainties tend to occur for the shallowest and deepest cells, and for the cells on the edges. In addition, cells on the edges of large contrasts in resistivity, as we have here, will tend to have greater sensitivities and uncertainties. This large contrast tends to occur in the Canterbury region at the transition to the resistive 
Journal of Environmental and Engineering Geophysics
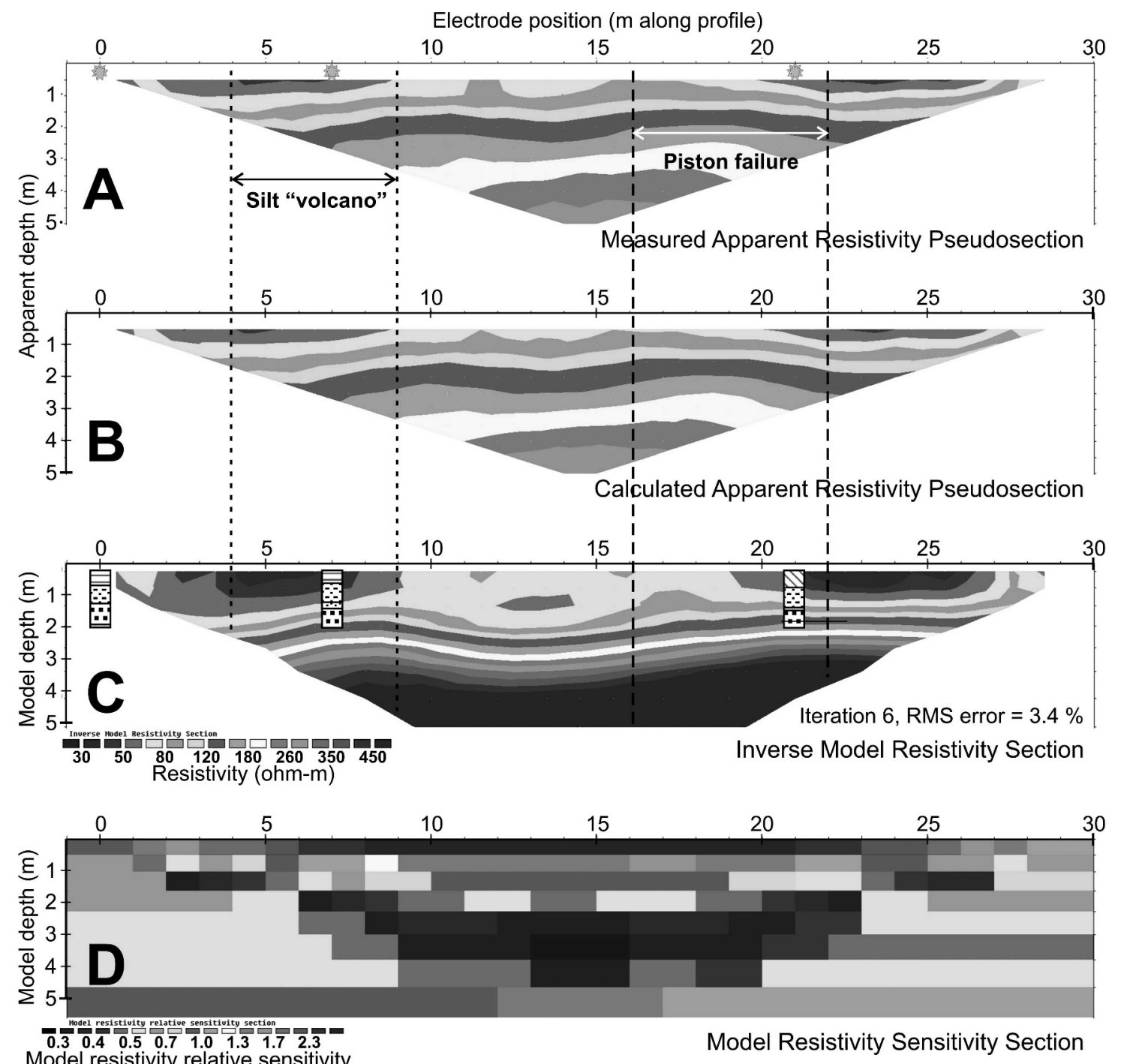

Model resistivity relative sensitivity

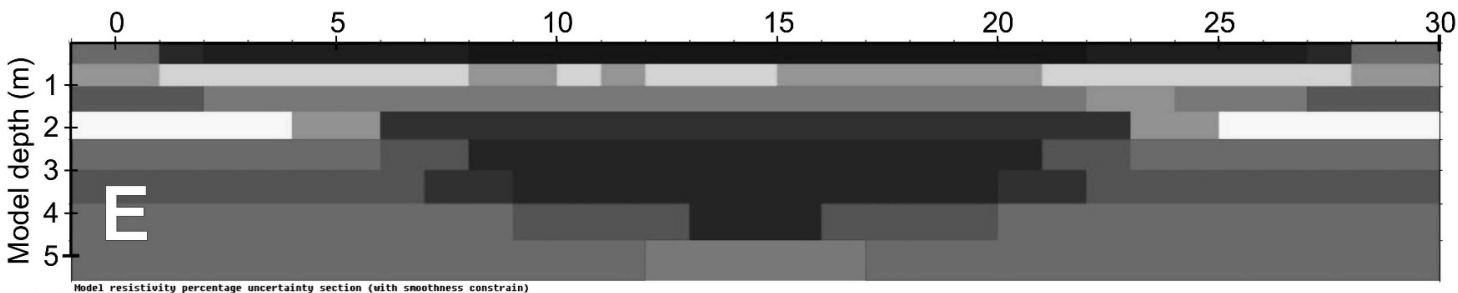

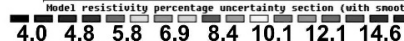

Model resistivity percentage uncertainty

Model Resistivity Uncertainty Section

Figure 5. The longitudinal Wenner electrical imaging profile illustrates the essential elements of all of the profiles. The raw measured response $(A$, top) is used in the modeling. The model response $(B)$ is compared to the measured response, and the misfit is minimized to yield the best-fitting model ( $\mathrm{C}$, middle). The lithology logs for (left to right) cores 1,2 and 4 (see Fig. 6) are superimposed on the best-fitting model for comparison. The uncertainties in the electrical resistivities for each of the model cells are calculated (D), as well as the sensitivities of the cells to changes in the measured responses ( $E$, bottom). See the text for a more detailed discussion. 


\section{Nobes et al.: Geophysical Imaging of Liquefaction Features}

saturated gravels that represent the aquifers for the region. We see such a transition here (Fig. 5(C)) and the sensitivities and uncertainties appear to be anomalously high at this high-contrast boundary.

The interpretation of the longitudinal profile is discussed in the next section, in the context of the crosssection electrical imaging profiles.

\section{Ground Penetrating Radar}

Ground penetrating radar (GPR) is now widely used and understood, and has been well described elsewhere (e.g., Davis and Annan, 1989; Bristow and Jol, 2003; Milsom and Eriksen, 2011). Briefly, a transmitting antenna sends a high frequency radar pulse into the ground, and a receiving antenna records amplitude (voltage) vs. two-way travel time (in nanoseconds, ns) for the direct waves through the air and the upper ground surface, and for the radar "echoes" that are returned from subsurface boundaries and discontinuities. At each position of the GPR survey, a trace of the response amplitude is recorded as a function of the travel time and each trace is plotted next to the previous trace. The result is a profile that looks like a geological cross-section, but is instead a record of the changes in the subsurface physical properties. GPR is particularly sensitive to changes in water content (see, e.g., Theimer et al., 1994) because water content dominates the subsurface propagation of radar waves. The water table is thus usually the most prominent GPR reflector.

The GPR data were acquired using a Sensors \& Software pulseEKKO 100A system. Test lines were run using both 100 and $200 \mathrm{MHz}$ antennas. The results indicated that the $100 \mathrm{MHz}$ data did not yield significantly better depth of penetration and sacrificed resolution. Thus, the GPR survey was completed using the $200 \mathrm{MHz}$ antennas.

The antennas were mounted on a sled with a constant separation of $0.5 \mathrm{~m}$. The sled was towed at a slow and relatively consistent speed to obtain common offset profiles. Fiducial markers were placed every $5 \mathrm{~m}$ along the survey lines and in the data files, both to monitor the towing speed and for later interpolation to a constant trace spacing. Towing speeds were generally slow enough to warrant a trace spacing of $0.05 \mathrm{~m}(5 \mathrm{~cm})$.

Velocity profiles using the common mid-point (CMP) were not acquired because of time and weather limitations. Few diffractions were noted, so limited velocity information is available. What diffractions there were suggest velocities of approximately 0.05 to $0.06 \mathrm{~m} / \mathrm{ns}(50-60 \mathrm{~m} / \mu \mathrm{s})$. Augering provided calibration of the water table, and from the calibrated depths velocities were estimated to be $0.06 \mathrm{~m} / \mathrm{hs}(60 \mathrm{~m} / \mu \mathrm{s})$. However, significant spatial variability was noted. The profiles were migrated using the calibrated velocity.
After trace interpolation ("rubberbanding") and migration, the files were gathered into 3-D data cubes. However, examination of selected profiles yielded as much information as the 3-D data cubes. Thus, profiles that are characteristic of the primary liquefaction features are used to illustrate the results, rather than attempting to show numerous slices through the 3-D data.

Half of the GPR lines were acquired one day and the rest were acquired the next day. One line, Line 21 (9.75 $\mathrm{m}$ along the longitudinal axis), was repeated to test the data quality and repeatability. The only differences observed were minor, and largely caused by small changes in the rate of data acquisition, i.e., the towing speed. The GPR data quality overall was good, based on consistency and repeatability.

\section{Augering}

Samples were acquired at selected correlation points (see Fig. 3) using a standard hand auger. The locations were selected to sample both the anomalous silt volcano and piston failure sites, and some control locations where the sediments might be relatively undisturbed.

Cores were obtained every $0.5 \mathrm{~m}$ down to refusal, which occurred between 1.8- and 2-m depth. As each core was acquired, it was removed from the cutter and laid in sequence on a sheet on the ground. The sediments were described and logged both for the site sedimentology description and for calibration of the geophysical responses.

At the refusal depth, core cutter grinding could be felt and heard in every case. Such grinding usually occurs when the cutter encounters rock or gravel. In a few cases, bits of gravel were recovered in the core. Given the context, we interpret the basal layer as gravel; of course the nature of the gravel, i.e., silty gravel vs. sandy gravel etc., could not be determined.

\section{Results and Discussion}

\section{Augering}

The auger results are presented first because the geophysical interpretation can then be made within the context of the known sediments and stratigraphy. The auger logs are shown in a 3-D perspective fence diagram (Fig. 6). Above each core is the core number. The core logs are shown in three columns. The first (left hand) column is the graphical lithology log. For example, in four of the five cores, the upper 40 to $50 \mathrm{~cm}$ consisted of topsoil, i.e., a relatively loose soil within which plant roots are present and direct air and water exchanges with the surface occur. The exception was core 4, which was taken just within what had been identified as a 
Journal of Environmental and Engineering Geophysics

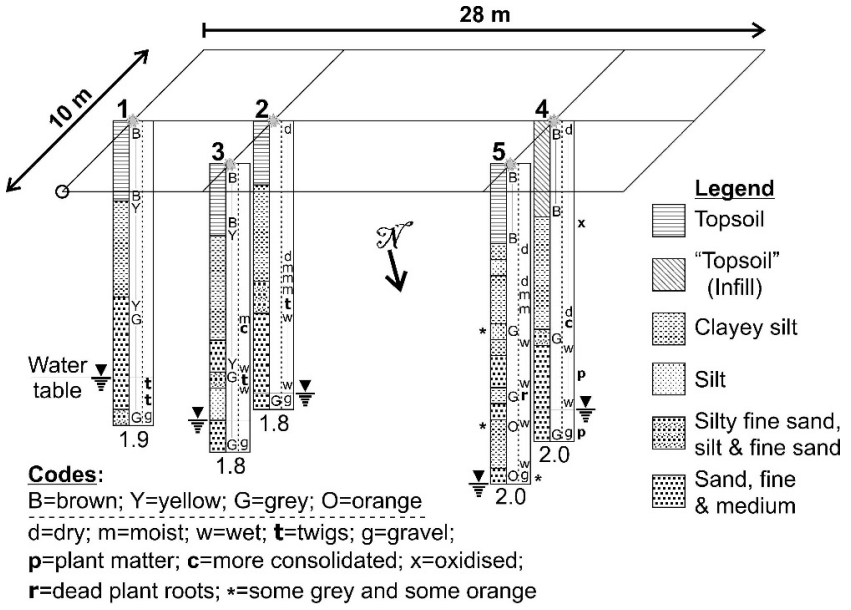

Figure 6. The auger results are presented in a 3-D fence diagram. The numbers above each core refer to the discussions in the text. The left hand portion of each column presents the lithology, as indicated by the legend key at the right. The second column is the color code, if recorded. The code key is at the bottom left. The third column presents codes representing any notes, such as the degree of moisture above the water table ("dry" vs. "moist" vs. "wet"), presence of twigs or plant matter, any oxidisation, etc. The results show both a broad degree of consistency as well as some local variability in the details. Note that core 4 , located at the site of the piston failure, has dry brown "topsoil" for a greater depth, and is thus interpreted as "fill".

piston failure. In that case, the "topsoil" was slightly thicker (about $60 \mathrm{~cm}$ ) and of a different material, a fine sand, which was interpreted as infill material used for remediation of the collapse feature. The second central column shows a color code, if the color was recorded. Thus, the upper layers were generally brown ("B"), whereas the basal layers were generally grey ("G"). The final column (on the right) contains codes that represent any notes of special significance, such as changes in moisture content above the water table (dry vs. moist vs. wet). For example, a bold " $t$ " indicates that twigs were found in the core. Such occurrences are often indicative of the bank of a stream.

The cores are relatively consistent across the site. There are subtle changes in the depths at which one lithology changes to another, and at which colors change. The water table occurs from depths of $1.6 \mathrm{~m}$ in core 1 (leftmost in Fig. 6) and core 3 (left front, Fig. 6) to $1.7 \mathrm{~m}$ in core 2 which was through the area of the silt volcano, $1.8 \mathrm{~m}$ in core 4 in the area of the piston failure (back right, Fig. 6), and $2.0 \mathrm{~m}$ in the northernmost core 5 (front right, Fig. 6). The twigs at depth in core 1 and at shallower depths in cores 2 and 3 are consistent with a location along the banks of a stream.

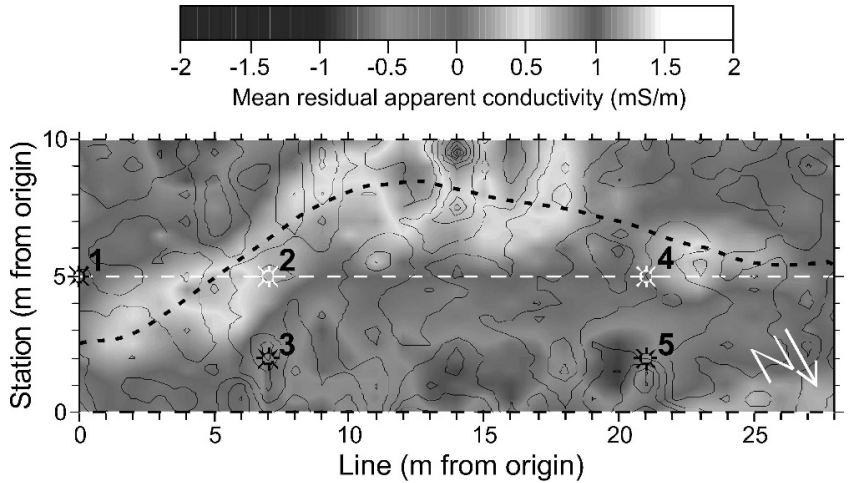

Figure 7. The residual mean EM31 apparent conductivity (base color image) has a high conductivity trend (bright zone, medium to pale grey) that curves across the southern (top) part of the site. The higher conductivities could be indicative of a buried paleochannel, which could provide a link between the liquefaction features. The approximate trend of the paleochannel is marked (dashed curve). The in-phase (real) response is also shown contoured, overlying the basal quadrature response. The real response has no obvious pattern. The auger locations are shown for comparison; the white auger symbols show locations within the liquefaction features. The central axis of the site is shown as a white dashed line.

\section{EM31}

The residual mean EM31 quadrature response, expressed as apparent conductivity in $\mathrm{mS} / \mathrm{m}$ (Fig. 7), is characteristic of the pattern of the responses observed for all of the HLEM modes. There is a clear higher conductivity trend that curves through the site, turning first towards the south (top) and then back towards the northwest (center right). The auger locations are shown so that their locations can be seen relative to the anomalous EM31 response. Auger core 2, taken $7 \mathrm{~m}$ WNW along the central axis of the survey, was on the western end of the silt volcano, and appears to be correlated with a higher conductivity anomaly at that location.

The piston failure was in the western half of the site. Auger core 4, taken $21 \mathrm{~m}$ WNW along the central axis, was on the western end of the piston failure feature. The piston failure appears to be on the boundary between the high conductivity trend to the south (top) and the lower conductivity to the north (bottom), that is, on the boundary of the inferred buried paleochannel.

\section{Electrical Imaging}

The six cross-section EI profiles (Fig. 8) show a progression from the site of the silt volcano (Lines 5 and 7, Fig. 8(A and B)) through an area between the surface expressions of the liquefaction features (Line 13, Fig. $8(\mathrm{C})$ ) to the area of the piston failure (Lines 17, 
Nobes et al.: Geophysical Imaging of Liquefaction Features
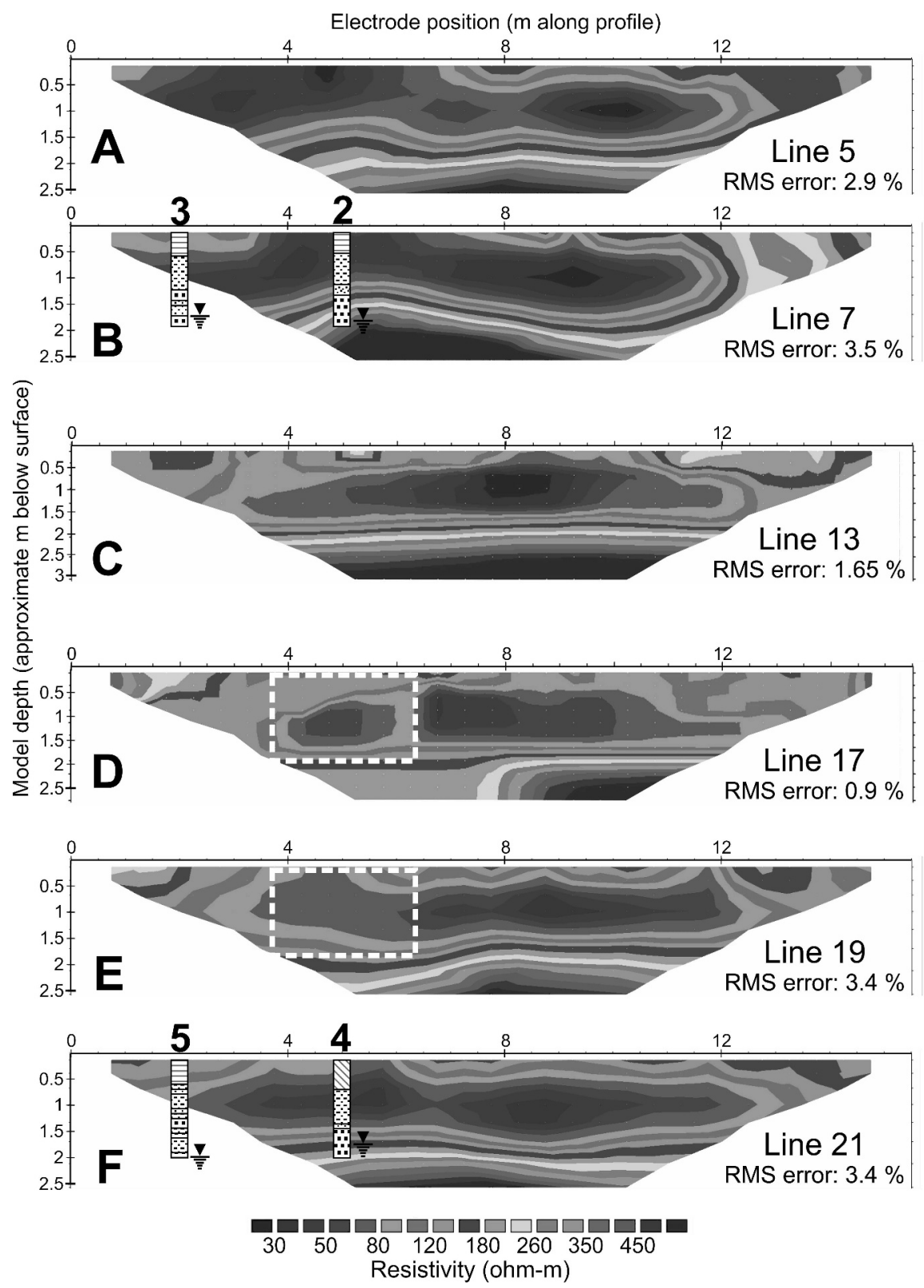

Figure 8. The cross-sectional electrical profiles show the progression from Lines 5 (A) and 7 (B), which cross the site of silt ejection, through the zone between the anomalous surface expressions of liquefaction, Line $13(C)$, to the piston collapse feature, which was crossed by Lines 17 (D), 19 (E) and 21 (F). The lithology logs from auger cores 2 and 3 (Line 7, B) and 4 and 5 (Line 21, E) are superimposed for comparison. The site of silt ejection is correlated with a shallower zone of higher resistivity, when compared to the site of low resistivity, which is located to the right (south) along Lines 5 and 7 (A and B). In contrast, the area of the piston failure (outlined by the bold dashed line in D and E) has slightly higher resistivity, reflecting the less compacted and drier fill material used to remediate the site.

19 and 21 in Fig. 8(D, E and F, respectively)). The auger core lithology logs for cores 2 and 3 are superimposed on Line 7 (Fig. 8(B)) and the logs for cores 4 and 5 are superimposed on Line 21 (Fig. 8(F)).

Lines 5 and 7 show what appears to be two zones of lower resistivity on either side of an area of higher resistivity that extends to shallower depths. This suggests that the silt ejection vent is located along the bank of what was a paleochannel. It is unlikely that the silt ejection would cause an increase in resistivity beneath the ejection vent, nor would the liquefaction cause the resistive material at depth to rise to shallower depths. Instead it would cause a decrease in surface elevation, as has been observed in careful GPS and 
Journal of Environmental and Engineering Geophysics

LiDAR measurements of surface elevation changes (Cubrinovski et al., 2010; Kaiser et al., 2012).

In contrast, Lines 17, 19 and 21 (Fig. 8(D, E and $\mathrm{F}$, respectively)), which cross the piston failure, show a slightly more resistive zone that appears to be coincident with the liquefaction feature (dash outline in Fig. 8(D and E)). This reflects the drier, less compacted fill material that was used in remediation, as identified in auger $\log 4$ (superimposed on Fig. 8(F)).

The less resistive feature that appears to the south (right) in all lines is likely associated with the more conductive curvilinear anomaly in the EM31 response (Fig. 7). This less resistive (more conductive) zone is interpreted as the response caused by a paleochannel.

\section{GPR}

Five representative GPR profiles have been selected to illustrate the basic elements present in the results (Fig. 9). Line 2 corresponds to a background line along the ESE baseline, and the lithology log for auger core 1 is superimposed (Fig. 9(A)). Line 12 (Fig. 9(B)) corresponds to Line 5 for the EM31 and EI results through part of the silt volcano location. Line 16 (Fig. 9(C)) also passes over the silt volcano location and corresponds to Line 7 for the EM31 and EI results; the lithology logs for auger cores 2 and 3 are superimposed. Line 28 (Fig. 9(D)) corresponds to Line 13 for the EM31 and EI results, and passed over the area between the surface expressions of the two liquefaction features. Finally, Line 36 (Fig. 9(E)) passes over the area of the piston failure, and corresponds to Line 21 for the EM31 and EI results. Only Line 36 is shown, because it yields the clearest GPR response across the piston failure feature.

Line 2 (Fig. 9(A)) is intended to be a background line, unaffected by the liquefaction features. The superposition of the lithology log from auger core 1 shows generally good correlation between the lithology boundaries and the GPR response profile. In particular, the water table nicely fits with what we interpreted in the field as the water table from the GPR response.

Lines 12 and 16 (Fig. 9(B and C, respectively)) illustrate features that were observed generally around the silt volcano. There is a shallow curved GPR reflector between 5 and $8 \mathrm{~m}$ along Line 12 that may be an old stream bank associated with a paleochannel. The feature is less prominent in Line 16, but the ejection vent was captured in the GPR response image (arrow in Fig. 9(C)).

Line 28 (Fig. 9(D)) is a second possible background line that lies between the surface expressions of the liquefaction features. It shows gently undulating subsurface reflectors, and the water table reflector at depth has what appears to be a variable depth.

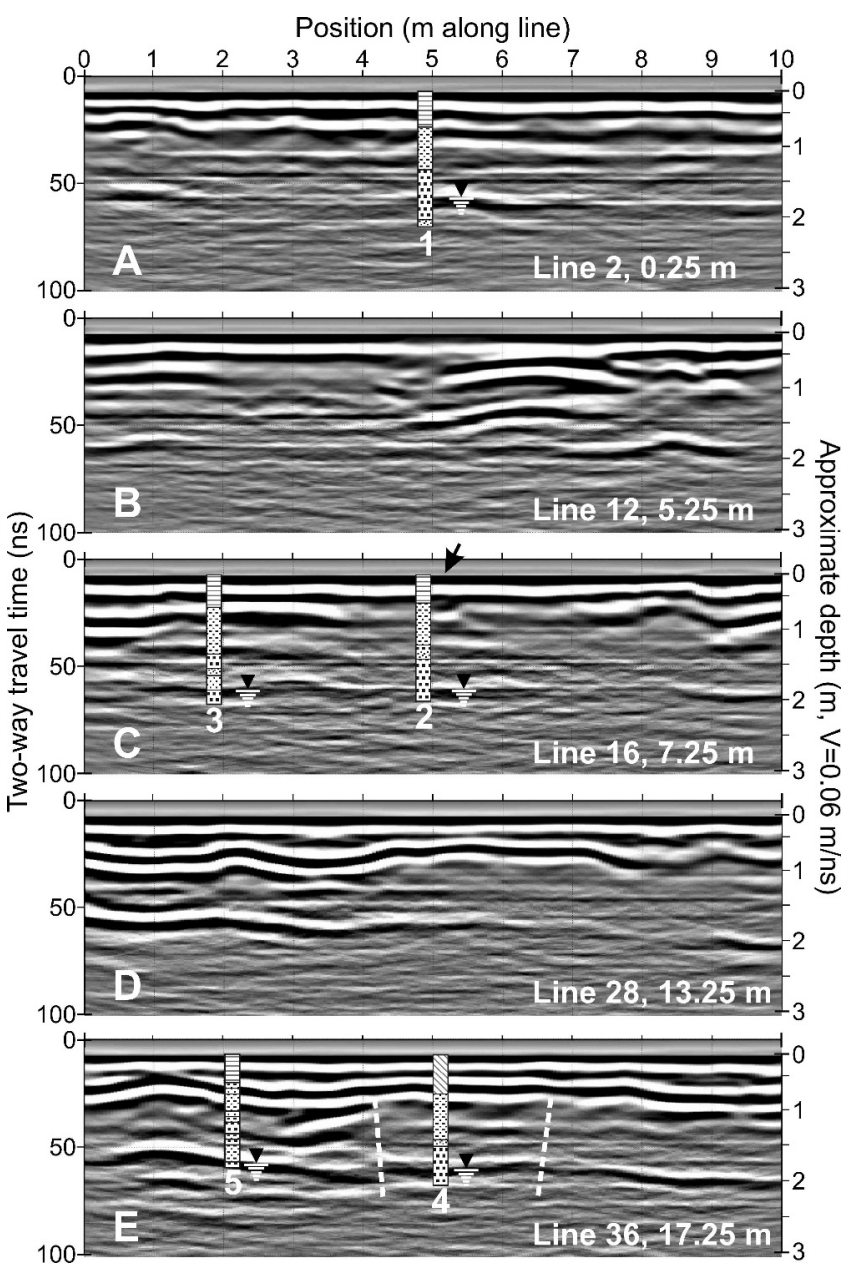

Figure 9. The GPR profiles for Lines 2 (A), 12 (B), 16 (C), 28 (D) and 36 (E) represent the different areas encountered across the survey site. Lines 2 and 28 (A and $\mathrm{D}$, respectively, equivalent to Lines 0 and 13 for $\mathrm{EI}$ and EM31) were across zones that were, in principle, background and largely unaffected by liquefaction. The water table is the major reflector, as it is for all of the lines. Lines 12 and 16 (B and C, respectively, equivalent to Lines 5 and 7 for EI and EM31) were across the zone of silt ejection. Line 12 shows a significant shallow reflector; Line 16 shows an anomalous response at a site of silt ejection that was wide enough to yield a GPR response. The lithology logs for auger cores 2 and 3 are superimposed for comparison. Line 36 ( $E$, equivalent to Line 17 for EI and EM31) crossed the piston failure zone. The lithology logs for auger cores 4 and 5 are superimposed. The basal watertable reflector appears to be sharply shallower beneath the piston failure, which we attribute to velocity "pull up" caused by the higher GPR velocity in the less compacted and drier material used to fill the piston collapse feature. 
Nobes et al.: Geophysical Imaging of Liquefaction Features

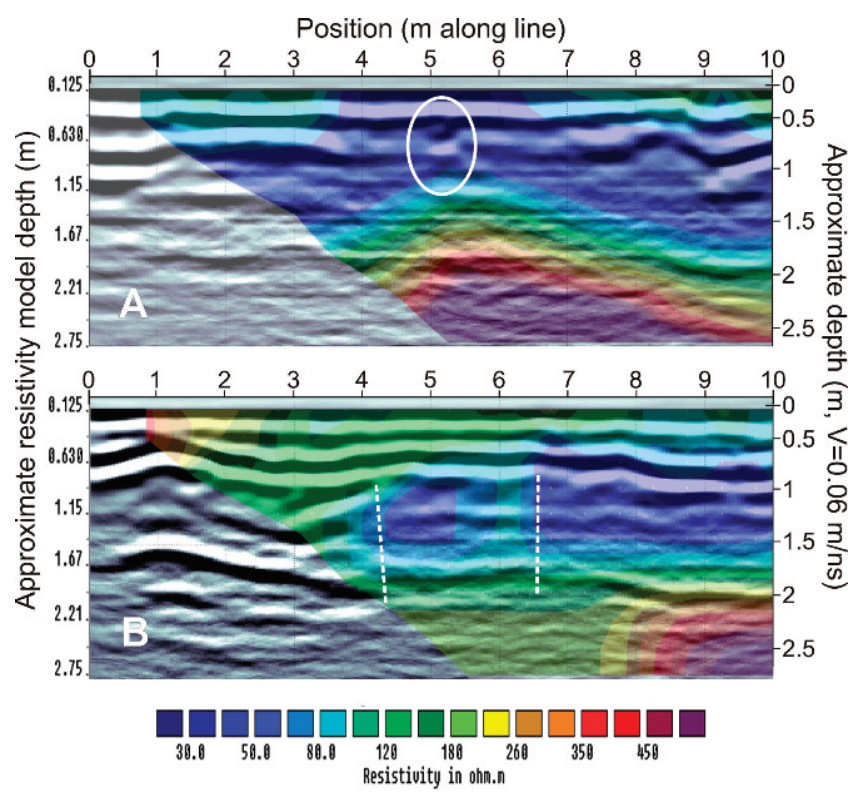

Figure 10. Composite of GPR profiles 16 (A, top) and 36 (B, bottom) overlain by the corresponding EI crosssections 7 ( $A$, top) and 17 (B, bottom). The EI images have been scaled and truncated so that the depth scales are the same and the same sections (distances) of each are presented. The profiles in A cross the silt volcano ejection location (circled), and the profiles in B cross the piston collapse feature. The apparent vertical offset is highlighted with the dashed lines in $B$.

However, we know from the auger core results that the water table varies by 10 's of $\mathrm{cm}$ at most, and the apparent changes in depth are more likely caused by a variable subsurface velocity. Changes in lithology and associated changes in moisture content can affect the GPR velocity.

Finally, Line 36 (Fig. 9(E)) crossed the piston collapse feature. There is a sudden change in the apparent depth to the water table, as highlighted by the nearly vertical dashed lines on either side of the sharply different water table reflector in Fig. 9(E). The fill material was drier and less compacted fine sand and soil. The lower water content and higher air content would cause an increased GPR velocity, which would result in velocity "pull up" caused by the decreased twoway travel time.

\section{Integrated Interpretation}

The combination of all of the results allows us to make a more comprehensive interpretation. For example, we can overlay the electrical imaging modeling results on the GPR profiles for the profiles that cross the silt volcano ejection site (Fig. 10(A)) and the piston collapse feature (Fig. 10(B)). The profiles have been scaled to have common depth scales, and shifted to align the positions along the profiles.

We have already noted that the boundaries for the EI and the GPR correlate well with the lithologic changes observed in the auger cores. What we can now see in Fig. 10 is that the physical property boundaries observed in the EI and GPR are also closely correlated. This serves to reinforce that the features we see are not artifacts of any aspects of acquisition or processing. We thus have more confidence in our interpretation of the features associated with the silt volcano and the piston failure features.

As already noted, the silt volcano in and of itself is unlikely to have distorted the subsurface boundaries to the extent observed in the EI and GPR profiles. It is more likely that the silt ejection vents followed existing lines of weakness or followed existing subsurface features, such as the edge of a buried paleochannel. The low resistivity zones in the EI results are in approximately the same locations as the high conductivity feature present in the EM31 results, which we have interpreted as a buried paleochannel.

Similarly, the piston failure appears to be located along the edge of the paleochannel, based on the EM31 results. The material used to fill the piston collapse feature during the remediation process was fine sand and soil, and was drier than the original material. Thus, the resistivity and the GPR velocity are consequently higher.

The locations of the liquefaction ejection vents and the piston failure adjacent to what appears to be a buried paleochannel suggest then that such zones of weakness are generated at the boundaries or transitions from one setting - a stream bed - to another - the banks of the stream. In hindsight, cores should also have been obtained from within what appeared to be a paleochannel, but two of the control cores are on its margins.

\section{Conclusions}

Following the Mw 6.2 earthquake in Christchurch, New Zealand, we investigated two liquefaction features that were located immediately adjacent to the sports grounds at Christchurch Boys High School. Results from EM31 horizontal loop EM mapping, electrical imaging, and ground penetrating radar profiling yielded subsurface responses that we could correlate with the surface silt ejection "volcano" vents and with the piston failure remediation. These features appear to occur on the margins of what we interpret as a buried paleochannel. The results suggest that the liquefaction features occurred on the boundaries between the paleochannel and its banks, not directly in the paleochannel itself. These results can be used to guide the remediation and 
Journal of Environmental and Engineering Geophysics

rebuilding of the affected areas of the city, so that sites susceptible to liquefaction can be avoided. In addition, existing buildings that may be susceptible to liquefaction can be identified.

\section{Acknowledgments}

The authors wish to thank Christchurch Boys High School and, in particular, Stephen Dods, their Director of Sports, for access to their grounds. We thank the Department of Geological Sciences of the University of Canterbury for their support of the field work, which began as a class project for the postgraduate course in Environmental and Engineering Geophysics. We particularly thank Matt Cockcroft for equipment preparation and logistical support, and Sacha Baldwin-Cunningham, Cathy Higgins and Vanessa Tappenden for arranging vehicles and other logistical support. DCN thanks the Institute of Geophysics and Geomatics at the China University of Geosciences in Wuhan for their kind and generous hospitality during a sabbatical visit. We thank the reviewers for their useful comments, which helped us to improve the manuscript.

\section{References}

Al-Shukri, H.J., Mahdi, H.H., and Tuttle, M., 2006, Threedimensional imaging of earthquake-induced liquefaction features with ground penetrating radar Near Marianna, Arkansas: Seismological Research Letters, 77(4) 505-513, doi: 10.1785/gssrl.77.4.505.

Bristow, C.S., and Jol, H.M., 2003, Ground penetrating radar in sediments: Geological Society of London, London, England, Special Publication Vol. 211, 330 pp.

Brown, L.J., and Weeber, J.H., 1992. Geology of the Christchurch urban area, Institute of Geological and Nuclear Sciences 1:25,000 Geological Map 1: Institute of Geological and Nuclear Sciences Limited, Lower Hutt, New Zealand.

Brown, L.J., Wilson, D.D., Moar, M.T., and Mildenhall, D.C., 1988, Stratigraphy of the late Quaternary deposits of the northern Canterbury plains: New Zealand Journal of Geology and Geophysics, 31(3) 305-335.

Cubrinovski, M., Green, R., Allen, J., Ashford, S., Bowman, E., Bradley, B.A., Cox, B., Hutchinson, T., Kavazanjian, E., Orense, R., Pender, M., and Witherspoon, L., 2010, Geotechnical reconnaissance of the 2010 Darfield (New Zealand) earthquake: Bulletin of the New Zealand Society for Earthquake Engineering, 43(4) 243-320.

Davey, F., 2011, Natural hazards - the Christchurch earthquakes: New Zealand Journal of Geology and Geophysics, 54(2) 139-150.

Davis, J.L., and Annan, A.P., 1989, Ground penetrating radar for high-resolution mapping of soil and rock stratigraphy: Geophysical Prospecting, 37(5) 531-551.

Field, G., Leonard, G., and Nobes, D.C., 2001, Where is Percy Rutherford's grave?: in Australasian Connections and New Directions: Proceedings of the $7^{\text {th }}$ Australasian Archæometry Conference, Jones, M., and Sheppard, P. (eds.), Research in Anthropology and Linguistics, University of Auckland, 5, 123-140.

Hsu, C.-C., Lee, D.-H., and Ku, C.-S., 2005. A case investigation of liquefaction features in a coastal industrial park by using ground penetrating radar: in Proceedings of the 15th International Offshore and Polar Engineering Conference, Seoul, Korea, 732-738.

Kaiser, A., Holden, C., Beavan, J., Beetham, D., Benites, R., Celentano, A., Collett, D., Cousins, J., Cubrinovski, M., Dellow, G., Denys, P., Fielding, E., Fry, B., Gerstenberger, M., Langridge, R., Massey, C., Motagh, M., Pondard, N., McVerry, G., Ristau, J., Stirling, M., Thomas, J., Uma, S.R., and Zhao, J., 2012. The Mw 6.2 Christchurch earthquake of February 2011: Preliminary report: New Zealand Journal of Geology and Geophysics, 55(1) 67-90, http://dx.doi.org/10.1080/00288306. 2011.641182

Kayen, R.E., Barnhardt, W.A., Ashford, S., and Rollins, K., 2000, Non-destructive measurement of soil liquefaction density change by crosshole radar tomography, Treasure Island, California: in Computer Simulation of Earthquake Effects, Arulanandan, K., Anandarajah, A., and Li, X.S. (eds.), American Society of Civil Engineers Geotechnical Publication 10, 52-65.

Kayen, R.E., Barnhardt, W.A., Ashford, S., Rollins, K., Minasian, D.L., and Carkin, B.A., 2005, High-resolution crosshole radar tomography: Application to liquefaction-induced change in soil on Treasure Island: USGS-PP 1658, URL: geopubs.wr.usgs.gov/prof-paper/ pp1658/ch2.pdf.

Liu, L., and Li, Y., 2001, Identification of liquefaction and deformation features using ground penetrating radar in the New Madrid seismic zone, USA: Journal of Applied Geophysics, 47, 199-215.

Liu, L., Li, Y., and Zhou, C., 2000, Identification of paleoliquefaction and deformation features with GPR in the New Madrid seismic zone: in Proceedings of GPR2000: 8th International Conference on Ground Penetrating Radar, Noon, D.A., Stickley, G.F., and Longstaff, D. (eds.), Proceedings of the SPIE, 4084, 383-389, http://dx. doi.org/10.1117/12.383597.

Loke, M.H., and Barker, R.D., 1996, Rapid least-squares inversion of apparent resistivity pseudosections by a quasi-Newton method: Geophysical Prospecting, 44, 131-152.

Maruya, D.M., Goyala, B., Patidara, A.K., Mulchandania, N., Thakkarb, M.G., and Chamyala, L.S., 2006, Ground penetrating radar imaging of two large sand blow craters related to the 2001 Bhuj earthquake, Kachchh, Western India: Journal of Applied Geophysics, 60(2) 142-162.

McNeill, J.D., 1990, Use of electromagnetic methods for groundwater studies: in Geotechnical and Environmental Geophysics, vol. I - Review and Tutorial, Ward, S.H. (ed.), Society of Exploration Geophysicists, Tulsa, Oklahoma, 191-208.

Milsom, J., and Eriksen, A., 2011. Field Geophysics, 4th ed.: John Wiley \& Sons, Chichester, England, 287 pp. 
Nobes et al.: Geophysical Imaging of Liquefaction Features

Nobes, D.C., 1999a, Geophysical surveys of burial sites: A case study of the Oaro urupa: Geophysics, 64(2) 357-367.

Nobes, D.C., 1999b, How important is the orientation of a horizontal loop EM system? Examples from a leachate plume and a fault zone: Journal of Environmental and Engineering Geophysics, 4, 81-85.

Nobes, D.C., 2007, Detecting linear features using the directionality of the HLEM response: in Proceedings of Near Surface 2007: $13^{\text {th }}$ European Meeting of Environmental and Engineering Geophysics, Istanbul, Turkey, Paper A23.

Nobes, D.C., and Wallace, L.R., 2007, Geophysical imaging of an early $19^{\text {th }}$ century colonial defensive blockhouse: in Proceedings of Near Surface 2007: $13^{\text {th }}$ European Meeting of Environmental and Engineering Geophysics, Istanbul, Turkey, Paper B10.

Reid, C.M., McCombe, J.Q., Thompson, N.K., Laird, T.E., and Irvine, J.R.M., 2010, Sub-surface expression of sand volcanoes in the Avon-Heathcote Estuary induced by the Darfield earthquake: Analog for sedimentary structures in the rock record: in Geoscience Society of New Zealand Annual Conference, Programme and Abstracts, Hoskin, P., Hikuroa, D., and Eccles, J. (eds.), Geological Society of New Zealand Miscellaneous Publication, 129A, p. 250.

Shulmeister, J., Soons, J.M., Berger, G.W., Harper, M., Holt, S., Moar, N., and Carter, J.A., 1999, Environmental and sea level changes on Banks peninsula (Canterbury, New
Zealand) through three glaciations- interglaciation cycles: Palaeogeography, Palaeoclimatology, Palaeoecology, 152(1-2) 101-127.

Sladen, J.A., D'Hollander, R.D., and Krahn, J., 1985, The liquefaction of sands, a collapse surface approach: Canadian Geotechnical Journal, 22, 564-578.

Tatsuya, K., Jun'inchiro, Y., Shin'ichi, K., Takao, M., and Yoshiaki, T., 2002, Ground disaster of Nishinomiya High School due to the 1995 Hyogo-ken Nanbu earthquake - The analysis of the artificial ground through the GPR survey: in Proceedings of the Japan Earthquake Engineering Symposium, 11, 931-936.

Theimer, B.D., Nobes, D.C., and Warner, B.G., 1994, A study of geoelectric properties of peatlands and their influence on ground penetrating radar surveying: Geophysical Prospecting, 42, 179-209.

Tuttle, M.P., Collier, J., Wolf, L.W., and Lafferty III, R.H., 1999, New evidence for a large earthquake in the New Madrid seismic zone between A.D. 1400 and 1670: Geology, 27, 771-774.

Wolf, L.W., Collier, J., Tuttle, M., and Bodin, P., 1998, Geophysical reconnaissance of earthquake-induced liquefaction features in the New Madrid seismic zone: Journal of Applied Geophysics, 39, 121-129.

Wolf, L.W., Tuttle, M.P., Browning, S., and Park, S., 2006, Geophysical surveys of earthquake-induced liquefaction deposits in the New Madrid seismic zone: Geophysics, 71(6) B223-B230. 